\title{
Een eerlijke klusseneconomie
}

\author{
Magda Smink, Joost Gerritsen, Arnoud Van Waes, Melanie Peters \& Rinie Van Est*
}

De tweede bijdrage van het Dossier over de klusseneconomie introduceert het begrip 'klusseneconomie' en beschrijft de opkomst van klusplatforms in Nederland. Vervolgens komt aan de hand van twee voorbeelden het functioneren van klusplatforms aan bod. Daarna verkennen we enkele belangrijke vragen over juridische onduidelijkheden, maatschappelijke effecten en de autonomie van online dienstverleners. Het slot van de bijdrage vat de belangrijkste effecten van de klusseneconomie samen en stelt dat deze effecten beleidsmakers en politici nopen tot het bepalen van eerlijke voorwaarden in een klusseneconomie.

\section{De klusseneconomie: begripsbepaling}

In mei 2017 publiceerde het Rathenau Instituut het rapport Eerlijk Delen (Frenken e.a., 2017), een onderzoek over het waarborgen van publieke belangen in de deel- en klusseneconomie. In dit artikel richten we ons specifiek op de klusseneconomie en baseren we ons op inzichten uit het Eerlijk Delen-rapport. We beschrijven hierbij de ons inziens belangrijkste gebeurtenissen die zich hebben voorgedaan na publicatie van het rapport tot medio februari 2018.

Het Rathenau Instituut definieert de klusseneconomie als dienstverlening door consumenten aan consumenten. Het gaat bijvoorbeeld om het aanbieden van persoonlijke diensten als een taxirit of een gekookte maaltijd. Het is een uitingsvorm van de bredere platformeconomie. De klusseneconomie dient te worden onderscheiden van de deeleconomie: 'het fenomeen dat consumenten elkaar gebruik laten maken van hun onbenutte consumptiegoederen, eventueel tegen betaling' (Frenken e.a., 2017, 7). Bij de klusseneconomie gaat het dus om diensten, bij de deeleconomie om goederen. Wordt de boor van een particulier geleend, dan is dat een voorbeeld van de deeleconomie, terwijl een particulier die voor iemand een gat in de muur boort illustratief is voor de klusseneconomie. Soms valt een activiteit echter in een grijs gebied. Zo zijn thuisrestaurants van ShareDnD grensgevallen. Hier wordt de eigen woning beter benut door gasten hiertoe toegang te geven (deelaspect), maar wordt er ook eigen tijd ingezet om te koken (een klus). Andere relevante platformeconomieën zijn de tweedehandseconomie (iemand koopt van een particulier een boor) en de product-diensteconomie (iemand huurt een boor van een bedrijf). De focus van dit artikel betreft de klusseneconomie.

Online platforms spelen een belangrijke rol in de klusseneconomie. Deze platforms brengen vraag en aanbod op overzichtelijke wijze samen en handelen ook

* Magda Smink is onderzoeker aan het Rathenau Instituut. Joost Gerritsen is advocaat bij Legal Beetle. Arnoud van Waes is promovendus aan de Universiteit Utrecht. Melanie Peters is directeur van het Rathenau Instituut. Rinie van Est is themacoördinator Slimme samenleving bij het Rathenau Instituut en onderzoeker aan de TU Eindhoven 
vaak de betaling af. Een platform onderscheidt zich van andere intermediairs door de aanwezigheid van kruislingse netwerkeffecten: het platform wordt aantrekkelijker voor gebruikers en dienstverleners - en vice versa. De gebruiker is de consument die de dienst afneemt van de dienstverlener via het platform. De meeste gebruikers zullen dus naar hetzelfde platform gaan, omdat dat de beste kans biedt op een 'match' en een lage prijs. Ook kan elkaars betrouwbaarheid op deze platforms vaak beter worden ingeschat, omdat dienstverleners al veel beoordelingen hebben gehad in het verleden.

Klusjes voor elkaar verrichten is van alle tijden. Voor de opkomst van online platforms verleenden mensen al vriendendiensten aan elkaar. De opkomst van online platforms heeft echter wel voor een belangrijke verandering gezorgd. De platforms hebben het voor mensen aantrekkelijk gemaakt om hun diensten aan te bieden aan vreemden. Een belangrijke functie van een klusplatform is het verbinden van en vertrouwen wekken tussen vreemden, om zo veel mogelijk transacties te bewerkstelligen. Zo worden - anders dan bij fysieke marktplaatsen - niet alleen vraag en aanbod bij elkaar gebracht, maar worden er ook beoordelingen achtergelaten, verzekeringen afgesloten, vinden online betalingen plaats en worden er (bezorg)diensten ingehuurd.

De economische logica van een online klusplatform kan worden begrepen aan de hand van transactiekosten (zoekkosten, contract- en controlekosten). Online platforms hebben de transactiekosten van het vinden van een dienstverlener of gebruiker drastisch verlaagd. Met name omdat je veel makkelijker dienstverleners of gebruikers kunt vinden dan voorheen. Om die reden zijn markten ontstaan voor de verhuur van spullen en het verlenen van diensten tussen vreemden die voorheen niet bestonden. Het tot een minimum beperken van de transactiekosten is van groot belang voor het platform, omdat lagere transactiekosten veelal leiden tot meer deelnemers en meer transacties, en zo tot navenant meer inkomsten. De meeste platforms verdienen per transactie of per bezoeker een bedrag of percentage. Commissies kunnen oplopen tot tientallen procenten van de aannamesom.

\section{Opkomst klusplatforms in Nederland en functioneren}

Sinds de introductie van Uber in 2012 is het aantal klusplatforms in Nederland snel gegroeid. Deze klusplatforms zijn met name for profit. In tabel 1 is een aantal bekende klusplatforms in Nederland opgenomen.

Wat opvalt is dat verschillende online platforms bedrijven zijn die opereren als onderdeel van een buitenlands concern. Zo komen Uber, Lyft en Amazon uit de Verenigde Staten en Helpling uit Duitsland. Deliveroo is Brits. Daarnaast staan de platforms bekend om de grote private investeringen die zij ontvangen. Van enkele miljoenen tot, in het geval van Deliveroo, honderden miljoenen euro's. Lyft en Uber ontvingen miljardeninvesteringen. Deze hoge investeringen impliceren dat investeerders verwachten dat de opbrengsten op termijn zeer groot zullen zijn 
Tabel 1 Klusplatforms in Nederland

\begin{tabular}{|c|c|c|c|}
\hline Naam & Land van oorsprong & $\begin{array}{l}\text { In Nederland } \\
\text { sinds }\end{array}$ & Type dienstverlening \\
\hline Uber & Verenigde Staten & 2012 & Taxidienst \\
\hline Croqqer & Nederland & 2013 & Platform voor lokale klussen \\
\hline Helpling & Duitsland & 2014 & $\begin{array}{l}\text { Huishoudelijke schoonmaak- } \\
\text { dienst }\end{array}$ \\
\hline UberPOP & Verenigde Staten & $\begin{array}{l}2014 \text { (in } 2015 \\
\text { verboden) }\end{array}$ & $\begin{array}{l}\text { Autovervoersdienst door chauf- } \\
\text { feurs zonder taxivergunning }\end{array}$ \\
\hline Deliveroo & Verenigd Koninkrijk & 2015 & Maaltijdbezorgdienst \\
\hline ShareDnD & Nederland & 2015 & Maaltijdbereiding door thuiskoks \\
\hline UberEATS & Verenigde Staten & 2016 & Maaltijdbezorgdienst \\
\hline Temper & Nederland & 2016 & Klusplatform voor horecasector \\
\hline Amazon's MTurk & Verenigde Staten & $\begin{array}{l}2016 \text { (voor } \\
\text { requesters) }\end{array}$ & Minitaken \\
\hline ASK \& TASK & Nederland & 2017 & Minitaken \\
\hline lemand.nl & Nederland & 2017 & $\begin{array}{l}\text { Huishoudelijke schoonmaak- } \\
\text { dienst }\end{array}$ \\
\hline
\end{tabular}

voor het platform. De geldschieters verwachten dus op enig moment rendement op hun investering.

We hebben eerder in deze bijdrage geconstateerd dat online platforms de koppeling tussen vragers en aanbieders van diensten automatiseert en dat transactiekosten afnemen. En we hebben laten zien dat ook in Nederland steeds vaker online platforms actief zijn. Maar hoe werken deze online platforms in de praktijk? We maken het functioneren inzichtelijker via een tweetal platforms: Helpling en (het inmiddels gestopte) UberPOP.

\section{Helpling}

Helpling is een digitaal platform voor huishoudelijke schoonmaakdiensten. Het bedrijf bemiddelt via de website tussen particuliere schoonmakers en particuliere huishoudens, waarbij het huishouden de schoonmaker inhuurt. Iemand die via Helpling wil schoonmaken, wordt niet zomaar toegelaten op het platform. Er volgt eerst een intakegesprek waarin het curriculum vitae (cv) en de ervaring worden besproken. Helpling hanteert beoordelingen op basis van de klanten-ratings en rekent 20 procent commissie van de som die een huishouden aan een schoonmaker betaalt. Er bestaat discussie over de rechtspositie van de schoonmaker. Het is de vraag of Helpling slechts als bemiddelaar of als werkgever optreedt. Dit juridische vraagstuk speelt zich af in de context van een huishoudelijke schoonmaakmarkt, waar veelal zwart werk wordt verricht. Hoewel sinds 2007 de Regeling Dienstverlening aan Huis geldt, die schoonmakers moet beschermen, functioneert deze niet goed. Helpling sluit expliciet aan bij deze regelgeving, die in de Nederlandse praktijk vaak omzeild wordt. Helpling is naar eigen zeggen geen werkgever, maar faciliteert gebruikers om volgens de Regeling Dienstverlening 
aan Huis te opereren. Dit betekent onder andere uitbetaling aan de dienstverlener van onder meer het wettelijk minimumloon en vakantiegeld en beperkte doorbetaling bij vakantie en ziekte. Helpling zoekt hiermee aansluiting bij de huidige regelgeving en neemt die als uitgangspunt voor een pleidooi voor vernieuwing. Mogelijk zal een rechter aangeven of Helpling de regelgeving correct naleeft in de zaak die de FNV met een schoonmaker tegen het platform is gestart.

\section{UberPOP}

UberPOP was een dienst van Uber die in 2014 en 2015 in Nederland beschikbaar was. De dienst bestond uit het aanbieden van ritten met een eigen auto. Deze ritten waren veel goedkoper dan reguliere taxi's. Reguliere taxichauffeurs vonden dat er sprake was van oneerlijke concurrentie. Deze chauffeurs moeten namelijk op basis van de 'taxiwet' voldoen aan diverse vereisten, zoals een blauw kenteken, het hebben van een chauffeurskaart en een boordcomputer. Omdat de UberPOPdienstverleners zich niet aan deze regels hielden, ontstond een ongelijk speelveld. De handhaving van de taxiregelgeving kwam, in de ogen van de reguliere taxichauffeurs, langzaam op gang. Uiteindelijk werden er boetes opgelegd en besluit Uber eind 2015 om met UberPOP te stoppen. In september 2017 bevestigde het College van Beroep voor het bedrijfsleven ( $\mathrm{CBb}$ ) dat de overheid terecht maatregelen tegen UberPOP genomen heeft. UberPOP was gericht op vervoer door particuliere chauffeurs zonder taxivergunning en daarmee op het overtreden van de wet, aldus het $\mathrm{CBb}$. De opstelling van Uber in deze casus ten aanzien van de weten regelgeving is opvallend. Deze regels werden bewust overtreden omdat zij volgens Uber onduidelijk en verouderd zouden zijn. Uber verklaarde na het stoppen van UberPOP dat deze activiteit slechts bedoeld was om een nieuw wettelijk kader voor meerijddiensten te creëren. Hiervoor ging het een juridische strijd aan en startte het een mediaoffensief. UberPOP lijkt hier bewust twijfel te hebben gezaaid om een gunstige marktpositie te verwerven voor het platform. Deze vrij agressieve wijze om veranderingen in de Nederlandse wet- en regelgeving te bewerkstelligen en de daarop volgende discussie hebben overigens deels succes gehad. Het ministerie van Economische Zaken gaf aan initiatieven van platforms als Uber experimenteerruimte te willen bieden binnen de bestaande regelgeving, ter bevordering van innovatie (Ministerie van Economische Zaken, 2015). Uber hanteert hierbij een andere insteek dan Helpling. Uber onttrok zich aan regelgeving.

\section{Vraagstukken in de klusseneconomie}

In deze paragraaf verkennen we enkele belangrijke vragen die de klusseneconomie oproept.

\section{Juridische onduidelijkheden}

Een belangrijk vraagstuk betreft de juridische status van de activiteiten van een klusplatform. Het is van belang om na te gaan welke wet- en regelgeving van toepassing is. Zo wordt helder waar verantwoordelijkheden liggen en hoe de plat- 
forms hun mandaat moeten verdienen (license to operate). Zijn online platforms slechts bemiddelaars of ook sectorbedrijven? Vrijwel ieder bekend klusplatform profileert zich als een dienst die 'slechts' bemiddelt in vraag en aanbod. De platforms zijn naar eigen zeggen geen sectoraal bedrijf. Zij zouden dus niet onder sectorale regelgeving en bijbehorend toezicht vallen. Consumentenbescherming kan daarmee in het geding komen. Bijvoorbeeld als hygiënevoorschriften niet worden nageleefd, terwijl deze wel van toepassing zijn in een bepaalde situatie. De praktijk van platforms verandert fundamenteel zodra een rechter of beleidsmaker duidelijk maakt dat zij zich aan de sectorale regelgeving dienen te houden. Naleving van deze wet- en regelgeving drukt de winstmarge. Volgens het kabinet moet per geval worden bekeken welke onderliggende diensten het platform zelf verleent, waarbij onder meer verschillende feitelijke en juridische criteria relevant zijn. Dit is ter beoordeling aan de rechter en - bij geschillen - aan het Hof van Justitie van de Europese Unie (HvJ EU). Daarnaast meldde het kabinet dat er nader onderzoek wordt verricht over de klusseneconomie. Hierin komen de feitelijke stand van zaken van de klusseneconomie en de mogelijke arbeidsrechtelijke, sociaalrechtelijke en fiscaalrechtelijke aspecten aan de orde.

In het geval van Ubers UberPOP-dienst heeft het HvJ EU een juridische knoop doorgehakt. In deze zaak hanteerde Uber het standpunt dat het geen taxibedrijf is, maar een 'dienst van de informatiemaatschappij'. Volgens de E-commercerichtlijn mag het verrichten van een dienst van de informatiemaatschappij niet afhankelijk worden gesteld van een voorafgaande vergunning of andere toelatingseis. Uber vond dat het mocht profiteren van dit versoepelde e-commerce-regime. Het HvJ EU ging hier niet in mee. Volgens het Hof is UberPOP een vervoersdienst. De EU-lidstaten mogen daarom voorwaarden stellen waaronder UberPOP mag worden aangeboden. In het rapport Eerlijk Delen riep het Rathenau Instituut de overheid op om de juridische status van platforms te verhelderen en daarmee ook hun verantwoordelijkheden. De zaak bij het HvJ EU over UberPOP heeft in totaal meer dan drie jaar geduurd. Gedurende die tijd bleef de status - en de daarmee gemoeide verantwoordelijkheid - van de dienstverlening ongewis. Het risico bestaat dat een platform hierdoor, al dan niet tijdelijk, de wet kan omzeilen.

Net zoals online platforms niet gezien willen worden als sectorbedrijven, beschouwen bijvoorbeeld partijen als Helpling en Temper zichzelf niet als werkgever. Dit is een tweede juridische onduidelijkheid. De kwalificatie van werkgever zou betekenen dat voor platforms en dienstverleners alle rechten en plichten gaan gelden gerelateerd aan een arbeidscontract. Dat houdt in dat het platform de gebruikelijke arbeidslasten dient te dragen, zoals loonbelasting, premies werknemersverzekeringen en loondoorbetaling bij ziekte. Die kosten drukken de winstmarges van het platform. Daarnaast genieten zelfstandigen niet dezelfde sociale bescherming als personeel in loondienst dat verplicht verzekerd is voor de publieke werknemersverzekeringen. Zelfstandigen zijn in principe zelf verantwoordelijk om zich te verzekeren tegen diverse risico's, zoals arbeidsongeschiktheid. Dit vraagstuk heeft dus veel impact op zowel de platforms als de dienstverleners. Per platform zal de invulling verschillen van de factoren voor beantwoording van de vraag of er sprake is van een arbeidsverhouding en tussen wie: de dienstverlener en het platform en/of de gebruiker. De meningen verschillen. 
Willem Bouwens, hoogleraar Sociaal recht aan de Vrije Universiteit, stelt dat dienstverleners van onder meer Uber en Deliveroo geen zelfstandigen zijn. Hij betoogt dat de dienstverleners een arbeidsrelatie kunnen hebben met de platforms. Het kabinet hanteert een afwachtende houding en stelt dat het aan de nationale rechter is om vast te stellen of in een concreet geval sprake is van een werknemersrelatie.

Een aanverwante discussie betreft schijnzelfstandigheid. Dit betreft de situatie waarin dienstverleners werkzaam zijn als zelfstandigen, maar de feitelijke werkomstandigheden wijzen op een dienstbetrekking. De praktijk van (schijn)zelfstandigheid waarin geen sociale lasten of verzekeringen worden betaald, is in strijd met het arbeidsrecht en leidt tot een ongelijk speelveld voor concurrerende platforms die wel trachten de arbeidsrechtelijke wet- en regelgeving na te leven. Platform Deliveroo wordt verweten bezorgers - fietskoeriers - als schijnzelfstandigen in te zetten. Concurrent Thuisbezorgd.nl heeft zijn koeriers in loondienst, die, in tegenstelling tot de andere bezorgdiensten, een fiets ter beschikking krijgen gesteld. Thuisbezorgd.nl vraagt dan ook om handhaving van de arbeidswetgeving door de Arbeidsinspectie. Als gevolg van het oneerlijke speelveld overweegt Foodora de zzp-constructie te gebruiken, zoals Deliveroo en UberEATS dat doen.

\section{Maatschappelijke vragen}

Naast juridische vragen roept de klusseneconomie maatschappelijke vragen op. Flexibilisering kan volgens het Sociaal en Cultureel Planbureau (SCP, 2016) de sociale cohesie in een samenleving verminderen en kan leiden tot nieuwe scheidslijnen op de arbeidsmarkt. Digitale techniek maakt het mogelijk om globale arbeidsmarkten te creëren. Hierin is het aanbod van dienstverleners groter dan de vraag. Dat kan leiden tot een situatie waarin een onderklasse wereldwijd concurreert om snippers werk, terwijl daar steeds minder tegenover staat (Kool \& Van Est, 2015). Er ontstaat een 'Mechanical Turk-economie'. Mechanical Turk is het internetplatform van Amazon waar mensen voor een klein bedrag een taak verrichten, zoals het classificeren van objecten of het labellen van foto's.

Een openstaande vraag betreft de invloed van de klusseneconomie op de welvaart, bijvoorbeeld ten aanzien van de welvaartsverdeling. De welvaart kan scheef worden verdeeld vanwege de potentiële monopoliemacht van de platforms. Hoewel platforms de markt inzichtelijker kunnen maken, komt dat niet per se de dienstverlener ten goede. Dienstverleners zien hun marktbereik mogelijk groeien, maar daarmee ook de concurrentie met andere dienstverleners. Dat kan betekenen dat prijzen dalen en daarmee arbeidsinkomsten teruglopen. Ook kunnen dienstverleners, zoals Uber dat wenst, mettertijd worden vervangen door robots, zoals zelfrijdende auto's.

De gebruiker kan profiteren van - aanvankelijk - lagere prijzen (die overigens deels mogelijk zijn door het omzeilen c.q. ontduiken van arbeids- en sectorwetgeving), maar de vraag is hoelang dat profijt blijft bestaan. Zo passen platforms een groeimodel toe dat gebaseerd is op het verzamelen van data. Deze data zijn grondstof voor de eigen algoritmen. Door netwerkeffecten en het databezit kunnen platforms snel groeien en daarmee marktmacht verkrijgen (Van Til, Van Gorp \& Price, 2017). Er geldt: winner takes all en de klusplatforms hebben monopolisti- 
sche tendensen. Monopolievorming betekent dat de welvaartsstijging die wordt gegenereerd door platforms, grotendeels zal toekomen aan de platforms in plaats van aan de dienstverleners en gebruikers. Het platform is dan in staat forse marges te rekenen per transactie, bijvoorbeeld via commissie- of prijsverhogingen.

Dataverzameling kan ook op een andere manier nadelig zijn voor de mededinging. Zo kan een platform concurrentiegevoelige informatie over dienstverleners verzamelen. Deze informatie kan vervolgens worden verhandeld aan partijen in andere sectoren, met mogelijke consequenties voor de kansen op werk voor die dienstverleners. Het feit dat de reputatie en vindbaarheid die een dienstverlener heeft opgebouwd bij een platform niet zomaar kunnen worden meegenomen naar een ander platform, zorgt voor een machtige positie van het platform. Hier spreekt men wel van reputatiemacht. Markttoezichthouder Autoriteit Consument en Markt (ACM) gaat zich de komende twee jaar extra richten op onder meer de machtspositie van platforms.

Werkenden die een zwakkere positie ervaren, komen overigens al in verzet. Zo hebben Deliveroo-bezorgers zich verenigd in de Riders Union. Ze eisen dat er gestopt wordt met de vervanging van bezorgers in loondienst door (schijn)zelfstandigen, dat er een cao wordt afgesloten, dat er een ondernemingsraad komt en dat tijdelijke contracten 'vast' worden. Zij organiseren stakingen. Voorheen legden arbeiders fabrieken plat, nu kan er druk worden uitgeoefend door af te spreken de app tijdelijk niet meer te gebruiken. Dit is niet eenvoudig. Mede-stakers zijn concurrenten. Ook bestaat de angst dat stakers van het platform worden verbannen.

\section{Autonomie}

Naast juridische en maatschappelijke effecten komt ook de individuele autonomie van dienstverleners door platformisering onder druk te staan. De mate van autonomie van een dienstverlener verschilt per platform. Het hangt ervan af of de dienstverleners een standaarddienst leveren, bijvoorbeeld bij de bezorging van maaltijden of personenvervoer. Maar als een thuiskok op verzoek maaltijden bereidt, dan bestaat juist veel invulling van de klus door de dienstverlener. Deze kok kan ook de menuprijs vaststellen binnen de voorwaarden die het platform daaraan stelt. Afhankelijk van het platform worden algoritmen ingezet om dienstverleners aan te sporen, te sturen of te surveilleren. In het boek Uber voor alles beschrijft journalist Rens Lieman (2018) hoe het is om een algoritme als baas te hebben, daarmee doelend op de platforms die via algoritmen invloed uitoefenen op de dienstverleners. Zo biedt Uber surge pricing, de automatische prijsverhoging van Uber-ritjes, als verwacht wordt dat veel mensen een rit willen maken op bijvoorbeeld een feestdag. Per sms'je spoort Uber de chauffeurs dan aan om te werken. De vraag is in hoeverre mensen die druk kunnen weerstaan.

Ook gebruikersbeoordelingen spelen een sturende rol. Wie goede beoordelingen heeft, heeft de grootste kans om nieuwe opdrachten te verwerven. Uber beloont positieve beoordelingen met badges, een methode uit de game-industrie om mensen naar doelen toe te laten werken. Dit is management door algoritmen: de door de dienstverleners gegeneerde data voeden de algoritmen, bieden inzicht in de prestaties en doen suggesties om de dienstverlener te sturen of te verleiden beter 
zijn best te doen. Wie volgens het platform te veel slechte beoordelingen ontvangt, kan worden verbannen.

Daarnaast is het inherent aan de app dat dienstverleners worden gesurveilleerd of digitaal gevolgd. Zo weet de gebruiker bijvoorbeeld waar de dienstverlener zich bevindt. De dienstverlener heeft geen keus: zonder surveillance kan er niet worden gewerkt. Surveillance heeft echter een chilling effect op de autonomie. Mensen hebben de neiging zich conformistisch te gedragen als ze constant in de gaten worden gehouden. Daarentegen kunnen dienstverleners soms ook anticiperen op het algoritme, om daarmee meer grip te krijgen op hun werk en inkomsten. Uberchauffeurs zouden in staat zijn om het prijsmechanisme te sturen (Möhlmann \& Zalmanson, 2017). Door massaal uit te loggen op een vooraf afgesproken tijdstip kunnen ze kunstmatig surge pricing opwekken. De chauffeurs delen online hun kennis hierover (Lieman, 2018).

\section{Eerlijke voorwaarden voor de klusseneconomie}

Platforms brengen vraag en aanbod bij elkaar, ze verlagen transactiekosten en creëren het benodigde vertrouwen in de markt tussen individuen. Wanneer een platform nog beperkt in omvang is, is gedogen vaak gerechtvaardigd, zodat er geleerd kan worden over publieke kansen en problemen. Wanneer klusplatforms snel groeien, loopt gedogen echter tegen grenzen aan. Dit geldt vooral omdat platforms, zoals we aan de hand van voorbeelden lieten zien, neigen naar monopolievorming en 'winner takes all'-effecten. De toekomstplannen van diverse platforms laten zien dat de klusseneconomie nog maar aan het begin staat. Zo beschouwt Uber zichzelf als aanbieder van mobility-as-a-service en wil het andere diensten dan taxiritjes aanbieden. Helpling wil uitbreiden naar meer soorten klussen en beschouwt de markt voor maatschappelijke ondersteuning als interessante groeimarkt.

De opkomst van de klusseneconomie laat nu al diverse negatieve effecten zien. Ten eerste zien we de opbouw van datamacht. Platforms brengen spelers van de vraag- en aanbodzijde samen. Daardoor krijgen ze data over gebruikers en dienstverleners die ze in hun voordeel kunnen gebruiken. Deze datamacht heeft verschillende soorten effecten. Er kan sprake zijn van uitsluiting van bepaalde klussen en van discriminatie, bijvoorbeeld op grond van ziekte of werkweigering. Ook zet de sturing als gevolg van management door algoritmen de autonomie van de dienstverlener onder druk. De datamacht kan ook leiden tot een scheve welvaartsverdeling, waarbij het grootste deel van de toegevoegde waarde bij het platform terechtkomt. De concentratie van data bij een klein aantal platforms doet de vraag rijzen of een dergelijke machtsconcentratie politiek gewenst is (Van Dijck, Van Poell \& De Waal, 2016). Ten tweede treedt het effect op van reputatiemacht. Reputatie en vindbaarheid die een dienstverlener heeft opgebouwd bij een platform, kunnen niet zomaar worden meegenomen naar een ander platform. Ook dit zorgt ervoor dat de dienstverlener zich in een relatief kwetsbare positie bevindt. Ten derde leidt de onduidelijkheid over de juridische status van klusplatforms als werkgever tot reële disruptieve effecten in de arbeidsmarkt. Grootscha- 
lige klusplatforms kunnen daarmee de levensvatbaarheid van bestaande bedrijven ondermijnen, omdat er op dit moment geen sprake is van een gelijk speelveld. Daarnaast zet de werkwijze van klusplatforms de kwaliteit van werk en de rechten van werknemers onder druk.

Dit alles maakt met betrekking tot de klusseneconomie de vraag urgent: hoe waarborgen we publieke belangen, zoals een eerlijke tariefstelling, kwaliteit van werk en de rechten van de dienstverleners? Rekening houdend met alle hierboven genoemde negatieve effecten van de klusseneconomie, dienen beleidsmakers en politici eerlijke voorwaarden te bepalen voor de klusseneconomie. Vanuit het perspectief van maatschappelijk verantwoord ondernemen mogen we van klusplatforms verwachten dat ze bovengenoemde negatieve effecten ook willen voorkomen. Tot nu toe lijkt het handelen van veel klusplatforms echter vooral bepaald te worden door winstmaximalisatie. Daarom pleiten wij voor de bevordering van alternatieve platforms, zoals non-profit platforms en coöperatieve modellen (Rathenau Instituut, 2017, 2018).

\section{Literatuur}

Dijck, J. van, Poell, T., \& Waal, M. de (2016). De Platformensamenleving. Amsterdam: University Press.

Frenken, K., Waes, A. van, Smink, M., \& Est, R. van (2017). Eerlijk delen. Waarborgen van publieke belangen in de deeleconomie en de kluseconomie. Den Haag: Rathenau Instituut.

Kool, L., \& Est, R. van (2015). Het gaat niet om technologie, het gaat om ons: Longread over werken in de robotsamenleving. Den Haag: Rathenau Instituut.

Lieman, R. (2018). Uber voor alles. Amsterdam/Antwerpen: Uitgeverij Business Contact.

Ministerie van Economische Zaken (2015). Ruimte voor vernieuwing door toekomstbestendige wet- en regelgeving (AEP/ 15079841).

Möhlmann, M., \& Zalmanson, L. (2017). Hands on the wheel: Navigating algorithmic management and Uber drivers' autonomy. Proceedings of the International Conference on Information Systems (ICIS 2017), 10-13 december 2017, Seoul, Zuid-Korea.

Rathenau Instituut (2017). Gespreksnotitie Werk in de platformeconomie. www.rathenau.nl/ $\mathrm{nl}$ /nieuws/werk-de-platformeconomie-rondetafelgesprek-de-tweede-kamer, geraadpleegd op 3 november 2017.

Rathenau Instituut (2018). Gespreksnotitie Rondetafelgesprek over deeleconomie. www. rathenau.nl/nl/nieuws/rondetafelgesprek-over-deeleconomie, geraadpleegd op 17 januari 2018.

SCP (2016). De toekomst tegemoet. Den Haag: SCP.

Til, H. van, Gorp, N. van, \& Price, K. (2017). Big data and competition. Rotterdam: Ecorys. 